\title{
Fatores de risco para acidentes de transporte terrestre entre adolescentes no Brasil: Pesquisa Nacional de Saúde do Escolar (PeNSE)
}

\author{
Risk factors for road traffic injury among adolescents in Brazil: \\ National Adolescent School-based Health Survey (PeNSE)
}

\author{
Otaliba Libânio de $\mathrm{M}$ orais $\mathrm{N}$ eto ${ }^{1}$ \\ Deborah Carvalho $\mathrm{M}$ alta ${ }^{2}$ \\ $M$ árcio Dênis M edeiros M ascarenhas ${ }^{2}$ \\ Elisabeth Carmen Duarte ${ }^{3}$ \\ M arta M aria Alves da Silva ${ }^{2}$ \\ Klívia Brayner de Oliveira ${ }^{4}$ \\ Cheila M arina Lima ${ }^{2}$ \\ Denise Lopes Porto ${ }^{1}$
}

${ }^{1}$ Departamento deAnálise de Situação deSaúde, Secretaria deVigilância em Saúde, Ministério da Saúde. SAF Sul, trecho 2, lote $5 / 6$ torrel, edifício Premium, sala 14, térreo. 70070-600 Brasília DF. otaliba.morais@saude.gov.br ${ }^{2}$ Coordenação Geral de Doenças eAgravos Não Transmissíveis, Secretaria deVigilância em Saúde, M inistério da Saúde.

${ }^{3}$ Universidade de Brasília.

${ }^{4}$ Instituto Brasileiro de

Geografia e Estatística.
Abstract Road trafficinjuries are the cause of an expressive number of deaths and hospitalizations among young people in the world. In Brazil, it is responsible for $17.1 \%$ of all deaths among adolescents aged 10 to 14 years. This article presents the results of the National Adolescent School-based Health Survey (PeNSE), using a probabilistic sample of students in the 9th grade of high schools (public and private) of the Brazilian capitals in 2009. The prevalence (and $95 \% \mathrm{Cl}$ ) of risk factors for road traffic injury among adolescents were estimated. M ain results from the 60,973 interviews were: in the last 30 days, $26.3 \%$ (25.5\% to $27.0 \% 95 \% \mathrm{Cl}$ ) reported no use of seat-belts while riding in a moving vehicle; $18.5 \%$ ( $18.0 \%$ to $19.1 \% 95 \% \mathrm{Cl}$ ) of youths younger than 18 years reported driving a motor vehicle ( $\geq$ once); $18.7 \%$ $(18.1 \%$ a $19.2 \% 95 \% \mathrm{Cl})$ reported a history of being driven by a driver who had been drinking ( $\geq$ once); and $35.0 \%$ ( $33.8 \%$ to $36.2 \% 95 \% \mathrm{Cl}$ ) reported no use of hel mets while riding a motorcycle ( $\geq$ once). The results are in accordance with the high rates of morbidity and mortality from traffic injury among youths, reinforcing the need of integrated intersectoral actions, specific legal measures and strict control.

Key words Road traffic injuries, Child, Adolescent, $\mathrm{H}$ ealth school, Adolescent behavior
Resumo $\mathrm{Os}$ acidentes de transporte terrestre (ATT) causam expressivo número demortes ehospitalizações entrejovens no mundo, sen do no Brasil responsável por $17,1 \%$ dos óbitos entre 10 e 14 anos. Este artigo apresenta resultados da Pesquisa Nacional de Saúde do Escolar (PeN SE), inquérito realizado em uma amostra probabilística de escolares do 9o ano do ensino fundamental de escolas públicas e privadas das capitais brasileiras, em 2009. Foram estimadasas prevalências (e IC95\%) das situações de risco para acidentes de transporte. Os 60.973 entrevistados indicam que (nos últimos trinta dias): $26,3 \%$ (IC95\% 25,5\%-27,0\%) referiram nunca ter usado cinto de segurança; $18,5 \%$ (IC95\% 18,0\%-19,1\%) dos menores de 18 anos referiram ter dirigido vé́culo motorizado ( $\geq 1 \mathrm{vez}$ ); $18,7 \%$ (IC95\% 18,1\%-19,2\%) referiram ter sido transportados em veículo conduzido por alguém que consumiu bebida alcoólica ( $\geq 1$ vez) e $35 \%$ (IC95\% 33,8\%-36,2\%) referiram não ter usado capacete pelo menos uma vez quando andava de motocicleta. Os resultados estão de acordo com as elevadas taxas de morbimortalidade de jovens no país por ATT, o que reforça a importância de ações educativas para adolescentes ea necessidadedeações intersetoriais integradas, além de legislação específica e fiscalização rigorosa.

Palavras-chave Acidentes de transporte/trânsito, Criança, Adolescente, Saúde escolar, Comportamento do adolescente 
Introdução

As cau sas externas de morbimortalidade (acidentes e violências) apresentam grande magnitudee impacto na vida das pessoas, por isso constituem um problema de grande relevância em Saúde Pública para a maioria dos países ${ }^{1-3}$. Entreas causas externas, os acidentes de transporte são responsáveis por expressivo número de mortes e hospitalizações. Segundo a Organização M undial da Saúde(OMS), em todo o mundo o número de pessoas que morrem a cada ano em decorrência dos acidentes de transporteéestimado em 1,2 milhão, o querepresenta aproximadamente $12 \%$ das mortes ${ }^{1}$. As estimativas apontam tendência crescente desses números, que deverão aumentar em $40 \%$ até 2030 , caso não sejam adotadas medidas preventivas 3 .

No Brasil, as taxas de mortalidade (TM ) por causas externas apresentam-se altas e crescentes desde a década de $1980^{4}$, o que demonstra a importância desse problema para o país. Somente em 2005, cerca de 127.600 brasileiros morreram em decorrência de causas externas, dos quais $36.611(28,7 \%)$ foram vítimas de acidentes de transporte (TM = 19,8/100.000 habitantes) ${ }^{4}$. $\mathrm{Na}$ faixa de idade de 10 a 14 anos, os acidentes correspondem a aproximadamente $17 \%$ dos óbitos desses jovens no Brasil4.

Os adolescentes são grupo estratégico de políticas de promoção à saúde e prevenção de doenças eagravos ${ }^{5}$. I sso porque, nessa época detransição entre a infância e a vida adulta, os jovens passam por mudanças profundas, buscando novas referências e se expondo, por vezes, a atitudes de risco. Esse comportamento está, por exemplo, associado a um aumento da incidência de acidentes eviolências, que podem resultar em lesões e incapacidades definitivas. Além disso, os danos causados por acidentes e violências correspondem a altos custos emocionais, sociais, com aparatos de segurança pública e, principalmente, gastos com assistência à saúde ${ }^{6}$.

O termo "acidentes" é pouco utilizado na literatura internacional, pela possibilidade de haver uma interpretação equivocada de que se trata dealgo al eatório ou imprevisível, por isso mesmo inevitável ou não passível de prevenção. Termos como crash e injury têm sido utilizados em língua inglesa por aparentemente não transmitirem essa conotação ${ }^{1}$. No Brasil, trabalha-se com o conceito de acidentes detransporte como evento não intencional, porém evitável. Esse conceito é importante por traduzir a não aleatoriedade do evento e a possibilidade de identificação de fatores condicionantes/determinantes para intervenção e sua prevenção.

M uitos são os fatores associados aos acidentes de transporte descritos na literatura, incluindo: aumento progressivo do número de automóveis circulantes, crescimento urbano por vezes desordenado, pouca tradição de educação para o trânsito, comportamentos de risco, desrespeito às leis de trânsito associado a eventual impunidade, fal has na legislação, más condições das vias de circulação, falta de manutenção dos veículos, condições climáticas desfavoráveis, álcool, entre outros ${ }^{5-9}$.

Entre os fatores protetores para os acidentes de transporte, a literatura cita o rigor na legislação relativa ao consumo de álcool associado à direção veicular, o uso dos testes de al coolemia, o limite imposto à velocidade veicular ${ }^{10,11}$, o uso de equipamentos de segurança, como cintos, capacetes, cadeirinhas de bebês e airbags, entre outros ${ }^{8}$. Porém, são ainda escassos os estudos sobre a identificação de fatores de risco e proteção para acidentes de transporte envolvendo jovens no Brasil. Evidências relativas à magnitude do problema e seus determinantes podem auxiliar sobremaneira o planejamento de ações de prevenção e a promoção de boas práticas no trânsito. Para preencher essa lacuna do conhecimento, - M inistério da Saúde e o Instituto Brasileiro de Geografia e Estatística (IBGE) realizaram, em 2009, a Pesquisa Nacional de Saúde do Escolar (PeN SE) ${ }^{12}$ com o objetivo de estimar prevalências de fatores de risco e de proteção à saúde do adolescente em relação a temas selecionados, entre eles a exposição a situações de risco para acidentes de transporte, eidentificar associações de interesse.

Este artigo tem como finalidade descrever a prevalência de fatores de risco para acidentes de transporte entre adolescentes de 13 a 15 anos de escolas públicas e privadas de capitais brasileiras e do Distrito Federal no ano de 2009, incluindo uso decinto de segurança, uso de capacetes, direção de veículo motorizado e tráfego em veículo dirigido por pessoa que havia consumido bebida alcoólica. Esses são comportamentos considerados de risco para acidentes de transporte, e evidências sobre sua magnitude e sobre os grupos mais acometidos entre os adolescentes podem ajudar a apoiar ações educativas dirigi das a esse público-alvo. 


\section{Métodos}

A população de estudo refere-se aos escolares do 9o ano do ensino fundamental ( $8^{a}$ série) de escolas públicas e privadas de todas as capitais dos estados brasileiros e do Distrito Federal.

0 tamanho da amostra para o estudo foi de $n=63.411$, o que permite estimativas de proporções (prevalências) das características de interesse em cada um dos estratos, considerando prevalências de $50 \%$, com um erro máximo de 0,03 (3\%) em valor absoluto e nível de confiança de $95 \%{ }^{12}$.

Para o plano amostral, inicialmente foram definidos 27 estratos geográficos correspondendo a todas as capitais de estados e Distrito Federal. A amostra de cada estrato geográfico foi alocada proporcionalmente ao número de escolas segundo a dependência administrativa das escolas ( privada e pública) ${ }^{12}$. Para cada um desses estratos, uma amostra de conglomerados em dois estágios foi selecionada como se segue: 1 음 estágio - escolas; 2ํㅡㄹ estágio - turmas elegíveis nas escolas selecionadas ( 90 ano do ensino fundamental). $N$ as turmas selecionadas, todos os estudantes presentes foram incluídos na amostra do estudo ${ }^{12}$. Para o sorteio das escolas e turmas, foi usado o cadastrado do Censo Escolar do ano de $2007^{13}$.

Os estudantes, assim selecionados, foram convidados a responder ao questionário da pesquisa, de forma anônima, individual ecom auxílio de um computador manual portátil (Personal Digital Assistant - PDA). 0 questionário era autoaplicável e apresentava perguntas estruturadas sobre fatores de risco e de proteção selecionados. A coleta de dados foi executada por equipes estaduais do IBGE entre março e junho de 2009. As informações coletadas alimentaram uma base de dados e foram analisadas com auxílio do pacote estatístico SPSS ${ }^{14}$.

Os resultados do conjunto das capitais brasileiras foram descritos segundo sexo, dependência administrativa da escola (pública ou privada) e local (capitais). Foi possível apresentar as prevalências (proporções) eseus respectivos interval os de $95 \%$ de confiança (IC 95\%) para os seguintes indicadores (construídos com base nas perguntas $(P)$ indicadas, sempre se referindo aos últimos trinta dias anteriores à data da pesquisa):

1) proporção de alunos que referiram nunca ter usado cinto de segurança ao utilizar veículos motorizados nos últimos trinta dias [P: Quantas vezes você usou o cinto de segurança quando estava em um carro ou outro veículo motorizado dirigido por outra pessoa (excluindo ônibus)?];
2) proporção de alunos menores de 18 anos de idade que referiram ter dirigido al gum veículo motorizado uma vez ou mais, nos últimos trinta dias [P: Quantas vezes você dirigiu um veículo motorizado de transporte (carro, motocicleta, voadeira, barco)?];

3) proporção de alunos que referiram ter trafegado em veículo motorizado dirigido por pessoa que havia consumido bebida alcoólica uma vez ou mais, nos últimos trinta dias ( P: Q uantas vezes você andou em carro ou outro veículo motorizado dirigido por alguém que tinha consumido alguma bebida alcoólica?);

4) proporção de alunos que referiram não ter usado capacete ao andar de motocicleta uma vez ou mais, nos últimos trinta dias (excluídos os que informaram não ter andado de motocicleta nos últimos trinta dias) ( $\mathrm{P}$ : Quantas vezes você usou um capacete ao andar de motocicleta?).

O estudo foi aprovado pela Comissão Nacional de Ética em Pesquisa (Conep) do M inistério daSaúde, com a Emenda no 005/2009 referenteao Registro no 11.537. 0 presente estudo se baseia em uma coleta de dados para fins de Vigilância em Saúde, a ser adotada deforma sistemática para o monitoramento da saúde dos escolares no Brasil. 0 Estatuto daCriança e do Adolescente(ECA) prevê a autonomia do adolescente para tomar iniciativas, tais como responder a um questionário, desde que este não ofereça risco à sua saúdee que tenha como objetivo claro o de subsidiar políticas de proteção à saúde para essa faixa etária. Em função disso, a Conep aprovou a isenção de consentimento expresso dos responsáveis pelos estudantes, ainda que menores de idade. A participação do estudante foi voluntária, tendo sido informado a el eque tinha liberdade para não participar ou para deixar de responder a parte ou a todo o questionário. Todas as informações do aluno, bem como as da escola, foram coletadas e mantidas em sigilo.

\section{Resultados}

Entreas 1.453 escolas amostradas, foram selecionadas 2.175 turmas ( 9 - ano do ensino fundamental), nas quais havia 72.872 al unos matriculados e um total de 68.735 alunos que frequentavam a escola. Destes, 63.411 (92,3\%) estavam presentes no dia da coleta de dados, totalizando $7,7 \%$ de perdas neste estágio (Figura 1 ). 
Foram ainda excluídos da amostra outros 501 estudantes por recusa e 1.937 estudantes por não preencherem a variável sexo. Finalmente, analisaram-se dados referentes a $60.973(88,7 \%)$ escolares, correspondendo a uma taxa de não resposta geral de $11,3 \%$.

$\mathrm{Na}$ amostra de escolares estudada, $89 \%$ dos alunos têm idade entre 13 e 15 anos, 47,5\% são do sexo masculino e $52,5 \%$ do sexo feminino, sendo $20,8 \%$ alunos de escolas privadas e $79,2 \%$ de escolas públicas. Um total de $26,3 \%$ (IC $95 \%$ : 25,5\%-27,0\%) dosescolares relatou não fazer uso de cinto de segurança quando estiveram em um veículo motorizado nos últimos trinta dias (Tabela 1). Adolescentes mulheres (28,7\%; IC $95 \%$ : $27,6 \%-29,8 \%)$ apresentaram maior proporção de não uso desse item de segurança em relação aos adolescentes homens (23,6\%; IC $95 \%$ : 22,5\%$24,6 \%)$. Além disso, estudantes deescolas públi- cas (29,2\%; IC 95\%: 28,2\%-30,1\%) referiram não usar cinto de segurança em maior proporção que estudantes de escolas privadas (18,6\%; IC $95 \%$ : $17,5 \%-19,7 \%$ ).

Verificou-sevariação importanteentreas prevalências de não uso do cinto de segurança entre adolescentes escolares segundo as capitais estudadas (Gráfico 1). A presentaram prevalências pontuais superiores a 30\% para esse indicador as seguintes capitais: região $N$ orte: $M$ anaus (44,2\%; IC95\%: 40,3\%-48,1\%), Palmas (35,0\%; IC95\%: 31,7\%-38,2\%) eM acapá (32,8\%; IC95\%: 30,1\%-35,5\%); região N ordeste: Teresina (32,5\%; IC95\%: 29,7\%-35,3\%), Salvador (31,3\%; IC95\%: 28,4\%-34,2\%) eSão Luís (30,7\%; IC95\%: 28,1\%$33,2 \%$ ); e região Sudeste: Rio de Janeiro (37,5\%; IC $95 \%$ : 35,0\%-40,1\%).

As menores prevalências desse indicador (<20\%) foram identificadas em: Vitória (18,2\%;

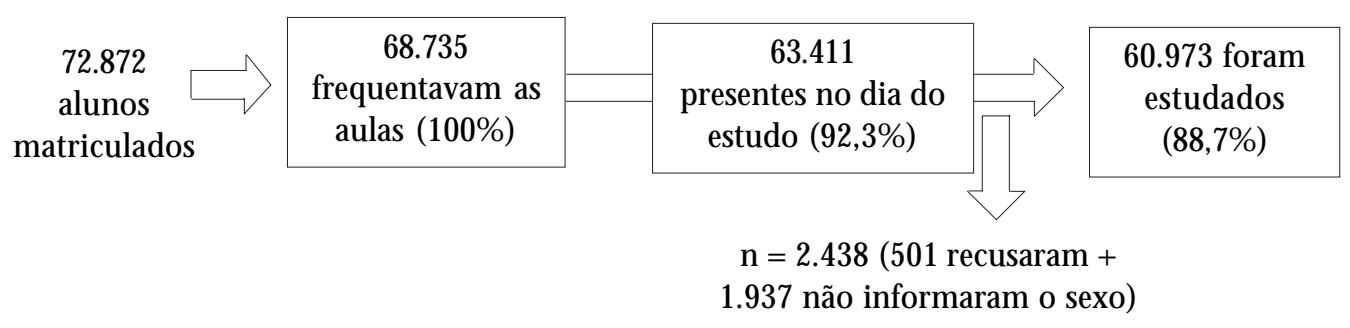

Figura 1. Taxa de participação dos adolescentes no estudo. PeN SE, 2009.

Tabela 1. Prevalência* (e respectivos I C95\%) de situações selecionadas de risco para acidentes de transporte (ocorrência pelo menos uma vez nos últimos trinta dias) referidas pelos escolares do 9o ano do ensino fundamental, segundo sexo e tipo de escola (pública ou privada). Capitais brasileiras, 2009.

\begin{tabular}{|c|c|c|c|c|c|c|c|c|c|c|}
\hline \multirow{3}{*}{$\begin{array}{c}\text { Situação de risco } \\
\text { para acidentes } \\
\text { de transporte }\end{array}$} & \multirow{2}{*}{\multicolumn{2}{|c|}{ Total }} & \multicolumn{4}{|c|}{ Sexo } & \multicolumn{4}{|c|}{ Dependência administrativa da escola } \\
\hline & & & \multicolumn{2}{|c|}{ Feminino } & \multicolumn{2}{|c|}{ Masculino } & \multicolumn{2}{|c|}{ Privada } & \multicolumn{2}{|c|}{ Pública } \\
\hline & $\%$ & (IC95\%) & $\%$ & (IC95\%) & $\%$ & (IC95\%) & $\%$ & (IC95\%) & $\%$ & $(I C 95 \%)$ \\
\hline $\begin{array}{l}N \text { ão uso de cinto de } \\
\text { segurança }\end{array}$ & 26,3 & $25,5 \quad 27,0$ & 28,7 & $27,6 \quad 29,8$ & 23,6 & $22,5 \quad 24,6$ & 18,6 & $17,5 \quad 19,7$ & 29,2 & $28,230,1$ \\
\hline $\begin{array}{l}\text { Direção de veículo } \\
\text { motorizado }\end{array}$ & 18,5 & $18,0 \quad 19,1$ & 9,0 & 9,5 & 29,3 & $28,3 \quad 30,2$ & 18,2 & $17,2 \quad 19,2$ & 18,6 & $18,0 \quad 19,3$ \\
\hline $\begin{array}{l}\text { Transportado por } \\
\text { quem consumiu álcool }\end{array}$ & 18,7 & $18,1 \quad 19,2$ & 17,8 & $17,1 \quad 18,6$ & 19,6 & $18,8 \quad 20,4$ & 23,8 & $22,7 \quad 24,9$ & 17,3 & $16,7 \quad 17,9$ \\
\hline Não uso de capacete** & 35,0 & $33,8 \quad 36,2$ & 34,3 & $32,7 \quad 36,0$ & 35,6 & $34,0 \quad 37,3$ & 34,1 & $31,6 \quad 36,8$ & 35,1 & $33,8 \quad 36,4$ \\
\hline
\end{tabular}

*Percentual ponderado para representar a população de escolares matriculados efrequentando o 90 ano do ensino fundamental em 2009. IC95\%: intervalo de confiança de 95\%; ${ }^{* *}$ Excluídos os que não andaram demotocicletas nos últimos trinta dias. 
IC95\%: 16,2\%-20,3\%), Porto Alegre (19,0\%; IC $95 \%$ : 16,5\%-21,4\%), Natal (19,7\%; IC $95 \%$ : 17,6\%-21,8\%) e Recife (19,7\%; IC95\%: 17,5\%21,9\%) (Gráfico 1).

$\mathrm{N}$ a população de estudo, a prevalência de estudantes menores de 18 anos que referiram ter dirigido veículo motorizado nos últimos trinta dias pelo menos uma vez foi de $18,5 \%$ (IC95\%: $18,0 \%-19,1 \%)$, com diferença estatisticamente significativa entre os sexos (Tabela 1): $29,3 \%$ (IC95\%: 28,3\%-30,2\%) entre os homens versus 9,0\% (IC95\%: 8,5\%-9,5\%) entreas mulheres. No entanto, as prevalências desseindicador não apresentaram diferença significativa segundo dependência administrativa da escola ( $18,2 \%$ nas escolas privadas versus $18,6 \%$ nas escolas públicas). Entre as capitais estudadas, as maiores prevalências foram observadas em Boa Vista (31,5\%; IC 95\%: 29,2\%-33,8\%), Palmas (28,6\%; IC 95\%: 26,3\%-31,0\%), Teresina (23,6\%; IC95\%: $21,8 \%$ $25,5 \%)$, Porto Velho (23,0\%; IC 95\%: $21,0 \%$ 24,9\%), Cuiabá( $22,8 \%$; IC $95 \%$ : 20,7\%-24,8\%) e Goiânia (22,4\%; IC 95\%: 20,8\%-24,0\%). As menores frequências foram observadas em Porto
Alegre(14,5\%; IC95\%: 12,6\%-16,3\%), Fortaleza (15,2\%; IC95\%: 13,7\%-16,8\%), Vitória (15,7\%; IC95\%: 14,0\%-17,3\%) e Belo H orizonte(16,5\%; IC95\%: 14,9\%-18,0\%) (Gráfico 2).

Ter sido transportado por veículo motorizado dirigido por motorista que consumiu bebida alcoólica nosúltimos trinta dias (pelo menos uma vez) foi referido por $18,7 \%$ (IC95\%: 18,1\%-19,2\%) do total de escolares estudados (Tabela 1). Esta situação foi referida em maior proporção pelos adolescentes homens (19,6\%; IC $95 \%$ : 18,8\%$20,4 \%)$ do que pelos adolescentes mulheres (17,8\%; IC95\%: 17,1\%-18,6\%), epelosadolescentes de escolas privadas (23,8\%; IC95\%: $22,7 \%$ $24,9 \%$ ) do que pelos adolescentes de escolas públicas (17,3\%; IC95\%: 16,7\%-17,9\%), evidenciando diferenças estatisticamente significativas. As capitais onde ocorreram maiores prevalências de transporte em veículo motorizado dirigido por motorista que consumiu bebida alcoólica referido pelos escolares estudados foram: Goiânia (23,4\%; IC 95\%: 21,8\%-25,0\%), Cuiabá (22,1\%; IC95\%: 20,1\%-24,2\%), Distrito Federal (21,6\%; IC95\%: 20,0\%-23,2\%), Campo Grande (21,3\%;

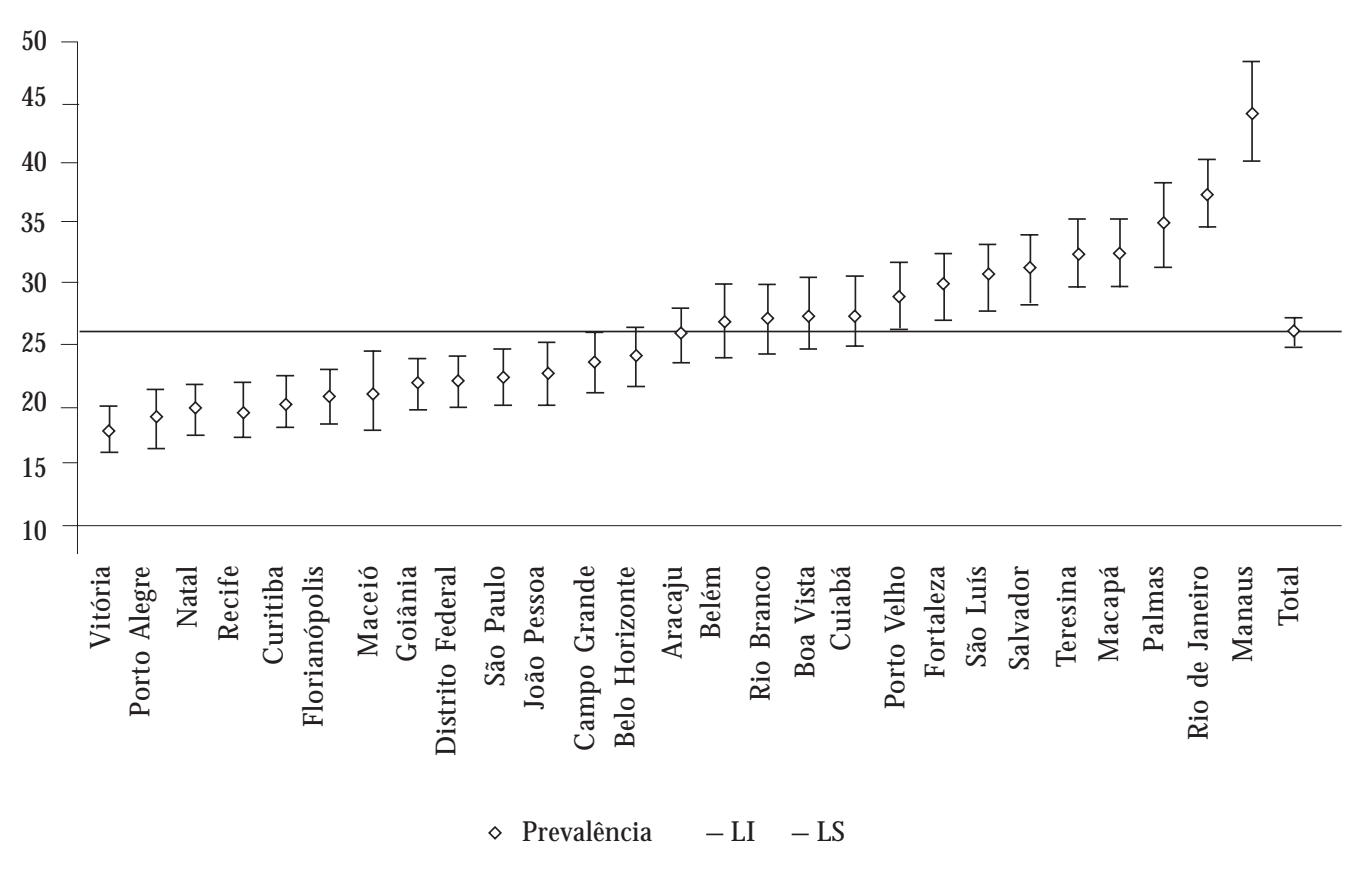

Gráfico 1. Prevalência (e respectivos IC $95 \%$ )* de não uso de cinto de segurança, quando se estava em veículo motorizado dirigido por outra pessoa (pelo menos uma vez nos últimos trinta dias), referida pelos escolares do 9o ano do ensino fundamental. Capitais brasileiras, 2009.

* Percentual ponderado para representar a população de escolares matriculados efrequentando o 90 ano do ensino fundamental em 2009. IC95\%: intervalo de confiança de $95 \%$. 
IC95\%: 19,4\%-23,1\%), Belo H orizonte (21,3\%; IC95\%: 29,6\%-23,0\%) eTeresina (20,8\%; IC $95 \%$ : $19,1 \%-22,6 \%)$. As menores prevalências foram registradas em $M$ anaus (14,4\%; IC95\%: 12,6\%16,2\%) eFortaleza (15,6\%; IC 95\%: 14\%-17,1\%).

A proximadamente $33 \%$ dos alunos relataram ter andado de motocicleta nos últimos trinta dias, sendo este meio detransporteutilizado por $29,4 \%$ das meninas e $36 \%$ dos meninos (dados não apresentados). Entre os escolares que andaram de motocicleta, 35\% (IC95\%: 33,8\%-36,2\%) referiram não ter feito uso decapacetenosúltimos trinta dias pelo menosumavez (Tabela 1). Essa prevalênciase manteve semelhante, independentemente do sexo ( $34,3 \%$ entremulheresversus $35,6 \%$ entrehomens) ou do tipo de escola (34,1\% nas escolas privadas versus $35,1 \%$ nas escolas públicas). Ascapitaiscom maiores prevalências denão uso decapaceteforam (Gráfico 4): Rio de Janeiro (68,1\%; IC 95\%: 64,6\%$71,4 \%)$, Salvador (52,3\%; I C95\%: 48,1\%-56,6\%), Belém (46,1\%; IC95\%: 42,1\%-50,3\%), Teresina (43,3\%; IC95\%: 40,2\%-46,4\%) e M anaus ( $41,7 \%$; IC95\%: 37,3\%-46,2\%). As menores prevalências foram observadas entre os estudantes de Campo Grande (10,1\%; IC95\%: 8,3\%-12,1\%) e Palmas (11,2\%; IC95\%: 9,2\%-13,6\%).

\section{Discussão}

A PeNSE, pela primeira vez, obtém informações nacionais sobre comportamentos e situações de risco para os acidentes de transporte terrestre entre escolares das capitais do Brasil. Os dados apresentados neste trabal ho mostram elevada frequência de práticas de risco, entre elas: nunca usar cinto de segurança, dirigir veículo motorizado mesmo sem ter idade para tal, ser transportado em veículo conduzido por alguém que tinha consumido bebida al coólica e não usar capacete quando andava de motocicleta pelo menos uma vez. Esses dados constituem a linha de base para o monitoramento desses comportamentos em jovens brasileiros e devem subsidiar políticas de promoção à saúde e prevenção desses agravos em adolescentes.

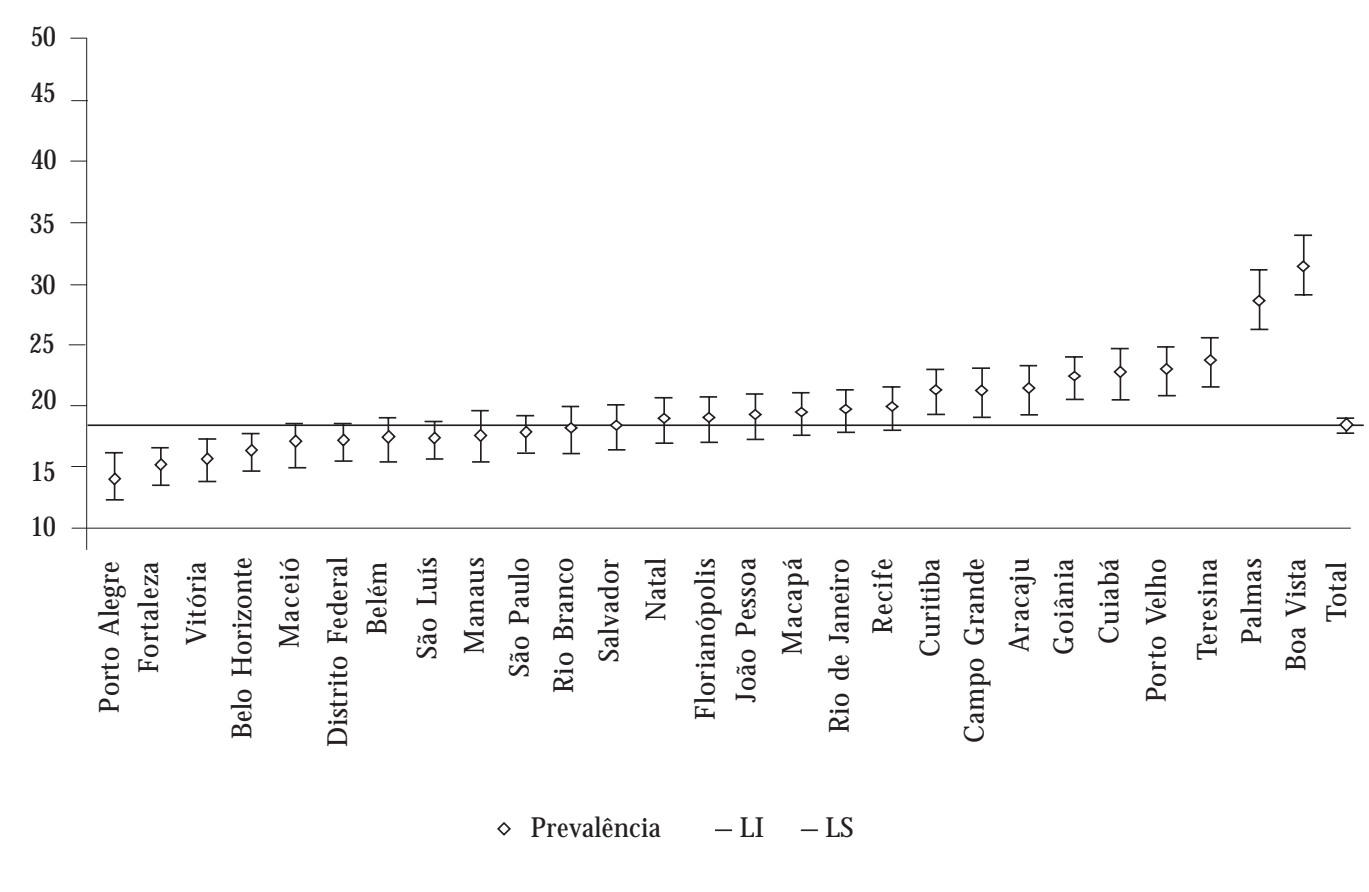

Gráfico 2. Prevalência (e respectivos IC 95\%)* de direção de veículo motorizado - carro, motocicleta, barco, voadeira (pelo menos uma vez nos últimos trinta dias) - referida pelos escolares do 90 ano do ensino fundamental. Capitais brasileiras, 2009.*

* Percentual ponderado para representar a população de escolares matriculados efrequentando o 90 ano do ensino fundamental em 2009. I C 95\%: intervalo de confiança de $95 \%$.

** Incluídos apenas os escolares com < 18 anos de idade. 


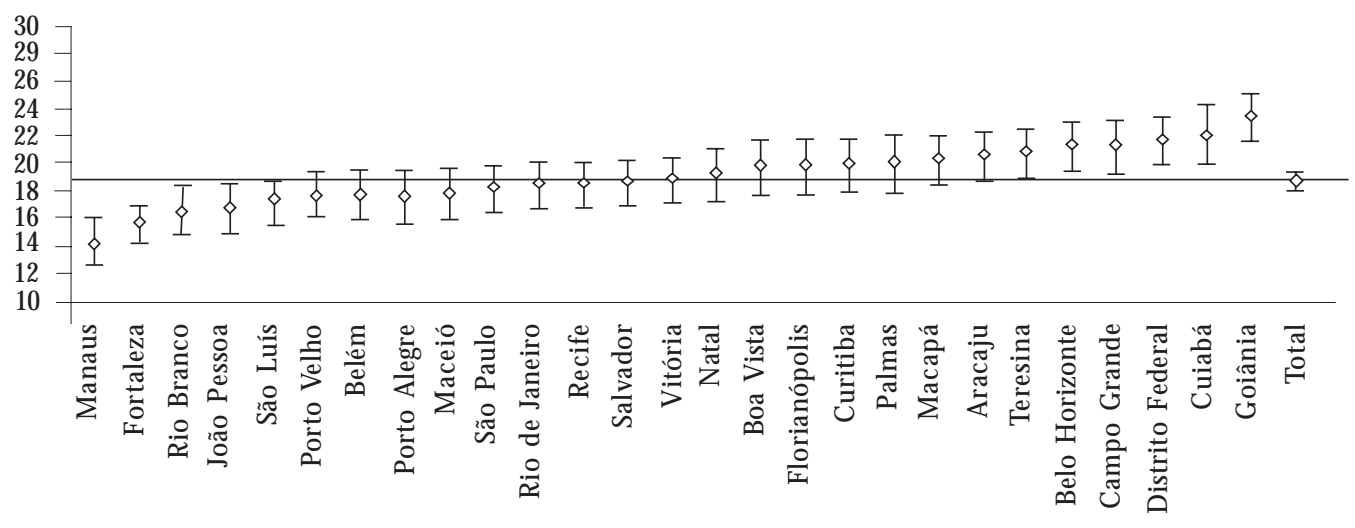

$\diamond$ Prevalência $\quad-\mathrm{LI} \quad-\mathrm{LS}$

Gráfico 3. Prevalência (e respectivos IC95\%)* de ser conduzido, em veículo motorizado, por alguém que havia consumido alguma bebida alcoólica (pelo menos uma vez nos últimos trinta dias), referida pelos escolares do 90 ano do ensino fundamental. Capitais brasileiras, 2009.

* Percentual ponderado para representar a população de escolares matriculados efrequentando o 9 a ano do ensino fundamental em 2009. IC 95\%: intervalo de confiança de 95\%.

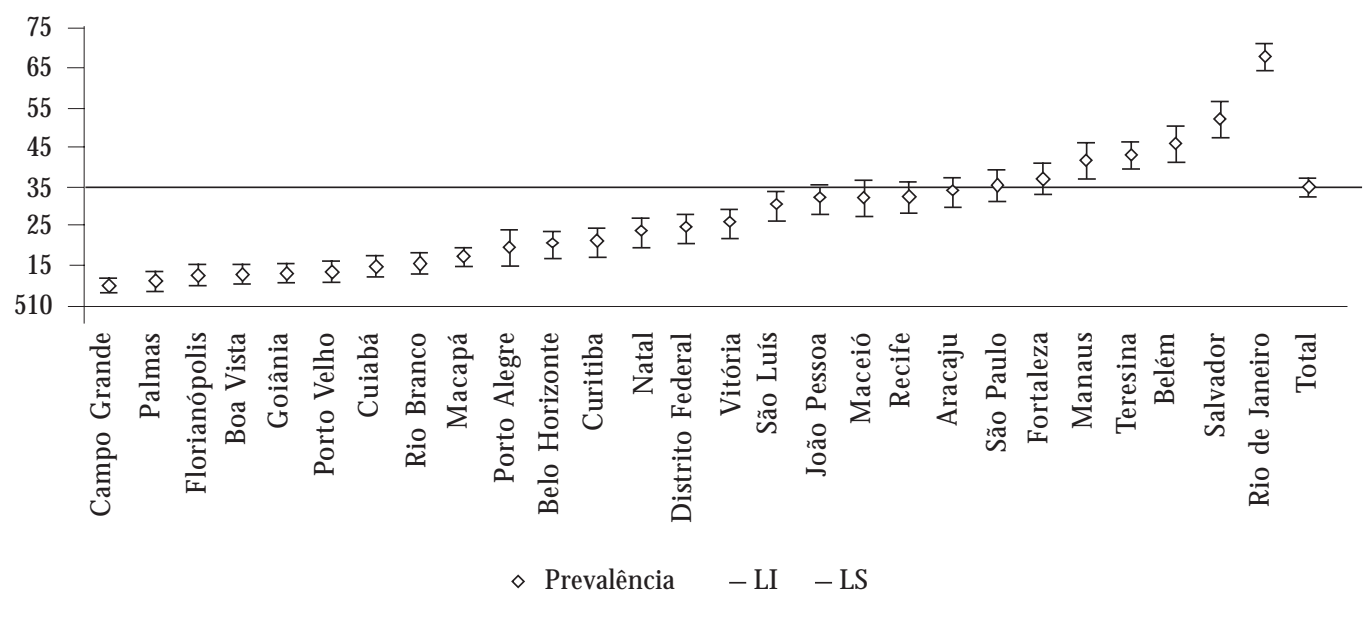

Gráfico 4. Prevalência (e respectivos IC95\%)* de não uso do capacete ao andar de motocicleta (pelo menos uma vez nos últimos trinta dias) referida pelos escolares do 9 o ano do ensino fundamental. Capitais brasileiras, 2009.**

* Percentual ponderado para representar a população de escolares matriculados efrequentando 090 ano do ensino fundamental em 2009. IC 95\%: intervalo de confiança de 95\%; ${ }^{* *}$ Incluídos apenas os escolares que referiram ter andado de motocicleta nosúltimos trinta dias. 
Destacamos quea direção deveículo motorizado por menores de 18 anos de idade relatada por $18,5 \%$ dos adolescentes, considerando que a maioria dos entrevistados tem entre 13 e 15 anos de idade, revela um fato preocupante. No Brasil, apenas aos 18 anos o cidadão é considerado apto a obter a habilitação de motorista. Esse cenário sugerea necessidade de investigar se há cumplicidade dos pais eresponsáveis em facilitar o acesso a tal prática.

A presenteanáliseidentificou, ainda, relato importante dos escolares adolescentes de transporte em veículo conduzido por alguém quetinha consumido bebida al coólica (18,7\%). Pesquisa realizada em 2007 pela Sociedade Brasileira de Ortopedia e Traumatologia (SBOT) ${ }^{15}$ com 1.034 jovens universitários de 18 anos ou mais em duas capitais (São Paulo e Rio de Janeiro) revelou que $42 \%$ dos jovens saem para se divertir regularmente, usam álcool edirigem, ou voltam com um conhecido que ten ha consumido bebida alcoólica.

Dos jovens pesquisados, 38\% revelaram já ter tido alguém de seu grupo envolvido em colisão de trânsito relacionada ao uso de bebida ${ }^{15}$. No entanto, afirmam que essa situação não resulta em risco, pois eles têm o sentimento de que nada irá acontecer a eles ${ }^{15}$, maximizando, desse modo, a exposição aos riscos.

Inquérito realizado nos Estados Unidos ${ }^{16} \mathrm{re}$ velou que $29,1 \%$ dos escolares relataram ter andado, nos últimos trinta dias, em veículo motorizado dirigido por alguém que tinha consumido bebida alcoólica.

Relatos de ter sido transportado por alguém alcoolizado foram mais frequentes entre os estudantes de capitais das regiões Centro-O este e Norte do país. Esse resultado concorda com os da pesquisa realizada por entrevistas telefônicas com a população adulta brasileira, em que as maiores frequências de consumo abusivo de álcool na população associado à direção veicular foram em: Aracaju, Teresina, Rio Branco, M acapá, Goiânia, Cuiabá, São Luís, Palmas e Porto Velho ${ }^{17,18}$. Esses dados apontam para a hipótese dequetal situação seja um hábito culturalmente aceito, o que podegerar sérias consequências para a população.

Existe um número de evidências de associação entreingestão de bebidas al coólicas eacidentes de transporte, assim como de proporções elevadas de vítimas de acidentes com histórico de consumo de bebidas alcoólicas, especialmenteno Brasi $\left.\right|^{9,19,20}$. Estudo multicêntrico com vítimas de causas externas não fatais, envolvendo dez países, mostrou que $18,1 \%$ das vítimas tinham in- gerido bebidas alcoólicas durante as seis horas que precederam o evento, sendo essa frequência mais baixa no Canadá ( $6 \%$ ) e mais alta na Nova Zelândia $(38,5 \%)^{19}$. N o Brasil, estudos mostram que aproximadamente metade das vítimas fatais de causas externas havia consumido álcool9,20,21.

Além disso, merece destaque a baixa adesão ao uso do cinto de segurança entre os jovens entrevistados ( $26,3 \%$ não usaram esse item de segurança nos últimos trinta dias). A falta de adesão ao uso de cinto de segurança aumenta sobremaneira a exposição dos adolescentes a acidentes de transporte com graves consequências. Dados da SBOT ${ }^{15}$ revelam que o cinto de segurança éusado por $96 \%$ dos estudantes de 18 anos ou mais, caindo para $93 \%$ quando estão no banco do carona e para apenas $11 \%$ no banco traseiro. A Pesquisa de Amostra de Domicílios 2008 (PNAD) ${ }^{22}$ do IBGE mostrou que o uso frequente do cinto de segurança no banco da frente foi declarado por $73,2 \%$ da população com mais de 14 anos, ao passo que o uso desse item no banco de trás é bem inferior: apenas 37,3\% referiram usálo sempre ou quase sempre. 0 fato de os estudantes entrevistados apresentarem, em sua maioria, idade entre 13 e 15 anos, e por isso usarem com frequência o banco detrás dos veículos, pode explicar, em parte, a baixa adesão aos cintos de segurança relatada por eles.

As evidências do benefício do uso do cinto no banco traseiro ou dianteiro na prevenção de acidentes e lesões têm sido amplamente discutidas na literatura23,24. Estudo realizado em 151 pacientes admitidos na sal a de emergência de um hospital-escola de São Paulo ${ }^{24}$ destacou que os passageiros nos bancos traseiros sem cinto de segurança mostraram grande suscetibilidade à ocorrência de fraturas de face, alertando para a necessidade de se tomar medidas de proteção para essa situação. Pesquisas discutem, ainda, o fato deque, quando os pais não usam o cinto de segurança, as crianças e os adolescentes também não o fazem, resultando em um ciclo vicioso ${ }^{5}$, o que indica quea mensagem sobre os benefícios desse equipamento deve ser dirigida a toda a família.

Outra prática analisada neste estudo foi a utilização do capacete, em razão das muitas evidências de queo uso desse equipamento protegecontra as lesões e sequelas dos acidentes de transporte. A pesquisa mostrou elevada proporção deadolescentes (35\%) que não utilizou o capacete, nos últimos trinta dias, ao andar de motocicleta. A falta de adesão a esse item de seguranca amplia as chances já elevadas de acidentes graves, mortes e incapacidades envolvendo motocicletas ${ }^{23}$. Existem 
relatos apontando que o uso rotineiro do capacetepara motociclistaseciclistaécomprovadamente capaz de reduzir a mortalidade em até $40 \%$ e os acidentes graves em até 70\%5,25,26. O Código de Trânsito Brasileiro indica a obrigatoriedade do uso de capacetes para motociclistas, mostrando a importância da fiscalização na indução de boas práticas no trânsito a esse respeito.

Foram encontradas diferenças relevantes entre as capitais brasileiras quanto ao relato de uso do capacete, com frequências de não uso superiores a $50 \%$ no Rio de Janeiro ( $68 \%$ ) e Salvador (52\%), em contraste com valores próximos a $10 \%$ em Campo Grande (10\%) e Palmas (11\%). Essas diferenças tal vez possam ser explicadas por falhas na fiscalização efatores culturais. A PNAD $2008^{22}$ chamou a atenção para o fato de as regiões N orte e N ordeste apresentarem maior proporção de acidentes entrecondutores demotocicletas, o que pode ser explicado tanto por ser um meio de transportebastantepopular quanto pelo não uso de capacetes. No entanto, os acidentes envolvendo motocicl etas têm setornado cada vez mais frequentes em diversas regi ões do país. Estudos apontam que as vítimas de acidentes com motocicleta chegam a representar $31 \%$ dos pacientes atendidos em emergências hospitalares ${ }^{27}$.

Entre os limites do estudo, a PeN SE foi realizada em capitais, portanto, a realidade de expo- sição aos fatores de risco referentes ao trânsito pode não corresponder ao encontrado em todo o país, em especial nas cidades do interior. Além disso, refere-se a escolares do 90 ano, podendo haver outras diferenças em relação aos adolescentes em outras faixas etárias, que não foram detectadas no atual estudo. 0 instrumento éautoinformado, mesmo tendo sido pré-testado; faz-se necessário avançar em estudos de validação do instrumento em diferentes realidades.

A redução do número de acidentes de trânsito e, consequentemente, de mortes, lesões, hospital izações eincapacidades ainda representa um desafio para a sociedade. Para tanto, processos indutores e fomentadores, incluindo medidas educativas, aprimoramento e implementação da legislação de trânsito, melhoria de rodovias e pesquisas, são fundamentais e devem ser ampliados para toda a populaçãa ${ }^{5}$. Conhecer a realidade epidemiológica dos acidentes de trânsito, incluindo as informações sobre as vítimas e a magnitudeedistribuição de seusfatores derisco, representa uma importante ferramenta para as políticas de promoção à saúde e prevenção, visando à redução de sua morbimortalidade ${ }^{1,28}$. Além disso, a abordagem de grupos estratégicos como o dos adolescentes parece ser oportuna para o desenvolvimento de uma cultura de paz no trânsito no Brasil.

\section{Colaboradores}

DC M alta trabalhou na concepção e no delineamento do estudo, na análise e interpretação dos dados, redigiu a primeira versão do artigo, trabal hou na sua revisão crítica e aprovou a versão a ser publicada. M DM M ascarenhas auxiliou na revisão de literatura, formatação do artigo e revisão final do texto. EC Duarte, M M A Silva, KB Oliveira eCM Lima contribuíram com a revisão de literatura e revisão final do texto. DL Porto realizou a extração ea análise dos dados e a revisão final do artigo. OL M orais N eto colaborou na discussão e na revisão final do texto. 


\section{Referências}

1. World Health Organization (WHO). World report on road traffic injury prevention. Geneva: WH O; 2004.

2. Peden $M$, M cGee K, Sharma G. The injury chart book: a graphical overview of the global burden of injury. Geneva: World Health Organization; 2002.

3. Mathers C, Loncar D. U pdated projections of global mortality and burden of disease, 2002-2030: data sources, methods and results. Geneva: World Health Organization; 2005.

4. Brasil, M inistério da Saúde, Secretaria de Vigilância em Saúde, Departamento de Análise de Situação em Saúde. Saúde Brasil 2007: uma análise da situação de saúde. Brasília: M inistério da Saúde; 2008.

5. Waksman RD, Pirito RM. O pediatra e a segurança no trânsito. J Pediatr (Rio J) 2005; 81(5 Supl):S181S188.

6. Mascarenhas M DM, Malta DC, Silva M M A, CarvaIho CG, Monteiro RA, Morais N eto OL. Consumo de álcool entre vítimas de acidentes e violências atendidas em serviços de emergência no Brasil, 2006 e 2007. Cien Saude Colet 2009; 14(5):1789-1796.

7. Souza $E R, M$ inayo $M C$, M alaquias JV. Violência no trânsito: expressão da violência social. In: Ministério da Saúde. Impacto da violência na saúde dos brasileiros. Brasília: M inistério da Saúde; 2005.

8. Souza ER, M inayo M C, Franco LG. Avaliação do processo de implantação e implementação do Programa de Redução da M orbimortalidade por Acidentes de Trânsito. Epidemiol Serv Saúde 2007; 16(1):19-31

9. Modelli MES, Pratesi R, Tauil PL. Blood alcohol concentration in fatal traffic accidents in the Federal District, Brazil. Rev Saude Publica 2008; 42(2):350352.

10. Hingson R, Winter M. Epidemiology and consequences of drinking and driving. Alcohol Res $\mathrm{H}$ ealth 2003; 27(1):63-78.

11. Souza M FM, Malta DC, Conceição GMS, Silva M M A, Gazal-Carvalho C, M orais N eto OL. Análise descritiva e de tendência de acidentes de transporte terrestre para políticas sociais no Brasil. Epidemiol Serv Saude 2007; 16(1):33-44.

12. Instituto Brasileiro de Geografia e Estatística (IBGE). Pesquisa Nacional de Saúde do Escolar - PeN SE 2009. Rio de Janeiro: IBGE; 2009.

13. Instituto Nacional de Estudos e Pesquisas Educacionais Anísio Teixeira (Inep). Censo Escolar 2007. Brasília: Inep [site na Internet] 2008 [acessado 2010 maio 21]. Disponível em: http://www.inep.gov.br/ imprensa/noticias/censo/escolar/news08_01.htm

14. Statistical Package for the Social Sciences for Windows Release 8.0.0. Chicago: SPSS Inc.; 1997. CD-ROM.

15. Sociedade Brasileira de Ortopedia e Traumatologia (SBOT). Comportamento no Trânsito entre jovens. São Paulo: SBOT [site na Internet] 2007 [acesso em 2010 jan 13]. Disponível em: http://www.sbot.org.br/ portal/N oticia/JovensTransito.asp

16. Centers for Disease Control and Prevention (CDC). National Youth Risk Behavior Survey (YRBS). Trends in behaviors that contribute to violence. $N$ ational YRBS: 1991-2007. Atlanta: CDC [site na Internet] 2008 [acessado 2009 set 15]. Disponível em: http:// www.cdc.gov/yrbss
17. M inistério da Saúde. Vigitel Brasil 2008: vigilância de fatores de risco e proteção para doenças crônicas por inquérito telefônico. Brasília: Ministério da Saúde; 2009.

18. Moura EC, Malta DC, M orais Neto OL, Penna GO, Temporão JG. Direção de veículos motorizados após consumo abusivo de bebidas alcoólicas, Brasil, 2006 a 2009. Rev Saude Publica 2009; 43(5):891-894.

19. National Highway Traffic Safety Administration. A review of the literature on the effects of low doses of alcohol on driving-related skills [monografia na Internet] [acessado 2009 jan 22]. Disponível em: http:/ /www.nhtsa.dot.gov

20. Gazal-Carvalho C, Carlini-Cotrim B, Silva OA, Sauaia N. Prevalência de alcoolemia em vítimas de causas externas admitidas em centro urbano de atenção ao trauma. Rev Saude Publica 2002; 36(1):47-54.

21. Freitas EAM, M endes ID, Oliveira LCM . Ingestão alcoólica em vítimas de causas externas atendidas em um hospital geral universitário. Rev Saude Publica 2008; 42(5): 813-821.

22. Instituto Brasileiro de Geografia e Estatística (IBGE). Pesquisa Nacional por Amostra de Domicílios - PNAD 2008. Rio de Janeiro: IBGE; 2010.

23. World Health Organization (WHO). Inequalites in young people's health: health behavior in school-aged children. International report from 2005-2006. Health Police for Children and Adolescents. $\mathrm{n}-5$. Geneva: WHO; 2008.

24. Fonseca ASF, Goldenberg D, Alonso N, Bastos E, Stochero G, Ferreira MC. Seating position, seat belt wearing, and the consequences in facial fractures in car occupants. Clinics 2007; 62(3):289-294.

25. Department of Transportation. National Highway Traffic Safety Administration. Evaluation of the repeal of the all-rider motorcycle helmet law in Florida. Florida: NHTSA [monografia na Internet] 2005 [acessado em 2010 maio 20]. Disponível em: http:// 204.68.195.151/people/injury/pedbimot/motorcycle/ FlaM CReport/images/FloridaM CReportscr1.pdf

26. Muller A. Florida's motorcycle helmet law repeal and fatality rates. Am J Public Health 2004; 94(4):556558.

27. M ello Jorge MH, Koizumi MS. Acidentes de trânsito no Brasil: breve análise de sua fonte de dados. Revista da Abramet 2001; 38:49-57.

28. Brasil, M inistério da Saúde, Secretaria de Vigilância em Saúde. Vigilância de acidentes e violências 2006-2007. Brasília: M inistério da Saúde; 2009.

Artigo apresentado em 30/05/2010

Aprovado em 15/07/2010

Versão final apresentada em 05/08/2010 